\title{
REDUCING A POSSIBILITY OF TRANSPORT CONGESTION ON FREEWAYS USING RAMP CONTROL MANAGEMENT
}

\author{
Roman Lagerev ${ }^{1}$, Denis Kapski ${ }^{2}$, Marija Burinskiené ${ }^{3}$, Andrius Barauskas ${ }^{4}$ \\ ${ }^{1}$ Dept of Management and Transport Logistics, Irkutsk State Technical University, Russia \\ ${ }^{2}$ Road Traffic Research Centre, Belarusian National Technical University, Minsk, Belarus \\ ${ }^{3,4}$ Dept of Urban Engineering, Vilnius Gediminas Technical University, Lithuania
}

Submitted 3 February 2016; resubmitted 1 May 2016; accepted 10 July 2016

\begin{abstract}
Merge junctions are the key elements in the freeway system, as they are likely to function as bottlenecks. Investigations into breakdown occurrence at ramp junctions have demonstrated that when the groups of several vehicles following each other enter the freeway from the ramp, they are expected to create 'turbulence' resulting from lane changes, decelerations of vehicles on the mainline and inevitably by the cars merging from the on-ramp. This turbulence can lead to breakdown when the level of mainline demand is adequately high. In other words, the impact of a ramp vehicle on capacity is higher than that of a mainline vehicle, which indicates that a part of vehicles will simultaneously occupy two lanes during the process of changing them thus momentarily decreasing the capacity of the link. This feature becomes particularly important near bottlenecks where it might reduce the already limited throughput. The article introduces the main approaches, methodology, principles and stages of transport demand management on freeways that are aimed at improving the operation quality of transport facilities, including road safety. The technique allows evaluating and optimizing a Ramp-Metering (RM) concept from the viewpoint of minimizing the length of queues on ramps and a possibility of transport congestion. The proposed algorithm estimates the probability of starting congestion formation on the ramp using objective information on traffic conditions in each segment of the highway, which is based on the criterion for vehicle density on the lane. The last chapter shows the examples of traffic flow optimization on Western bypass ramps in Vilnius comparing two strategies for access control management using one or several vehicles per lane. Conclusions, trends and work on future investigations are presented at the end of the article.

Keywords: O-D trip matrix estimation; elimination of recurrent congestion; intelligent transportation systems; access control management; bottlenecks; breakdown flow; ramp control management.
\end{abstract}

\section{Introduction}

In the last century, the rate of motorization significantly increased, which caused traffic slowdowns and congestions that were the most prominent problems in the urban road network.

In recent decades, urban highways have become common in growing cities. Urban highways are planned to provide a bypass to the urban road network thus absorbing a part of its traffic. Over the years, urban highways have been progressively integrated into the road network and urban environment (Gregurić et al. 2014). The limited capacity of recent urban road networks is a consequence of inability to expand their volume due to limited economic and physical resources (Papageorgiou et al. 2003). Increased traffic demand is forcing to optimize the usage of the existing road traffic infrastructure.
The employment of intelligent transport systems is the best way to achieve optimization.

Freeways have free basic segments: a freeway, a ramp junction and a weaving area. The ramp junction is the most common area where changes in driver's behaviour may occur. The drivers traveling near the ramp along the lane often have to slow down to allow vehicles from the ramp to merge onto the freeway, whereas at the off-ramp junction, drivers may need to shift lanes or allow others to shift them to make the exit. Such in and out flows at ramp junctions often cause drivers to change lanes (Park, Roess 2015).

The breakdown phenomenon at on-ramp junctions has been identified as a probabilistic phenomenon (Park, Roess 2015). Breakdown probability at on-ramp junctions is higher as ramp flow ratio increases (Shawky, Nakamura 2007). Also, due to the above introduced lane

Corresponding author: Andrius Barauskas

E-mail: andrius.barauskas@vgtu.lt 
interactions some lanes prematurely enter the queue discharge state without reaching their free-flow capacity (Ringert, Urbanik 1993). Therefore, the merging behaviour and lane changes at ramp have a negative influence on the area and a high on-ramp flow contribute adverse impacts at on-ramp junctions (Sun et al. 2014).

The possibility of transport congestion on freeways can be reduced using various methods. Ramp-Metering (RM) and variable speed limit control are solutions used in the majority of cases.

Although RM has proved to be the most effective and practical method of traffic control techniques, it has major limitation: queues at the ramp should not spill over to the adjacent infrastructure. Ramp storage space may be limited, and therefore RM is typically released when the ramp queue has covered the whole on-ramp. Thus, RM may delay the onset of congestion, accelerate its dissolution and reduce its space extent; also, it may have to be deactivated for most of the peak period due to full ramps (Papamichail et al. 2010).

Ramp management strategies may be used for controlling access to the selected ramps from which vehicles enter a freeway (Jacobson et al. 2006).

The basic operation principle of high-speed roads of higher categories is laid in Russian regulatory documents on design. The principle is a provision of a separate and safe traffic flow. It can be achieved only by following requirements for modern guidelines on network access control. Therefore, the presence of tendencies for developing control methods through the main streets and roads using adaptive re-regulation with automatic monitoring of traffic flow can be noticed. The roads of higher categories must bear large volumes of urban traffic movements. The principle 'concept of concentration' is an integral part of modern development and a growth in large urban settlements and is laid in a long-term programme for developing transport systems in a number of Russian and foreign cities (Mihajlov, Golovnyh 2004).

Conceptual approaches to the management of traffic on the roads of higher categories are determined in the Highway Capacity Manual (2010) (HCM) of American leadership. The document describes in detail a procedure for evaluating the performance of high-speed roads, conditions and causes for the formation of congestion on them. The service level of traffic on the roads of higher categories is reduced to estimating the values of traffic density in the highway segments (Fig. 1) of the backbone network (Table 1) (Lorenz, Elefteriadou 2001).

HCM lays the foundation for consistently preserving a smooth and safe traffic flow. The primary objective is assessing the probability of forming recurrent congestion on the streets and roads of higher categories taking into account available information on traffic demand, which leads to creating tools necessary to manage them.

The task of predicting traffic congestion can be performed using the products of the micro simulation of traffic flows (Hasan et al. 2002) or using the theory of the probability of failures in the work of a queuing system that has been preferred by the authors of the article.

Fig. 2 presents the results of studying the influence of the main and ramp streams (Lorenz, Elefteriadou

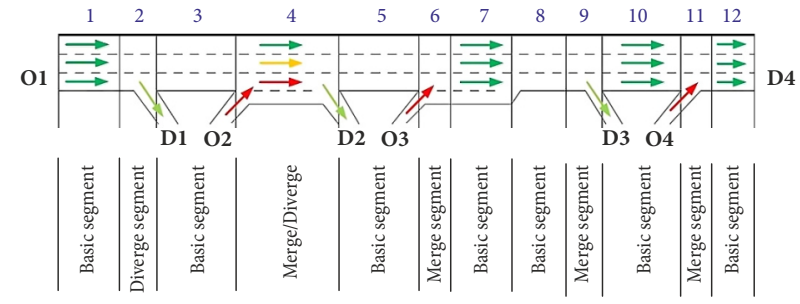

Fig. 1. The differentiation of highway segments (Highway Capacity Manual 2010)

Table 1. Recommended boundary values of traffic flow on highways (Highway Capacity Manual 2010)

\begin{tabular}{|l|l|l|}
\hline \multicolumn{1}{|c|}{ Highway segment } & $\begin{array}{l}\text { Effectiveness } \\
\text { index }\end{array}$ & $\begin{array}{l}\text { Boundary values of } \\
\text { the index }\end{array}$ \\
\hline $\begin{array}{l}\text { Area of the main } \\
\text { sections (baseline } \\
\text { segments) }\end{array}$ & $\begin{array}{l}\text { Density } \\
\text { [veh/km/lane] }]\end{array}$ & $\begin{array}{l}\text { Necessary to reduce } \\
\text { availability on upper } \\
\text { ramps when traffic } \\
\text { density }>29\end{array}$ \\
\hline $\begin{array}{l}\text { Area of interweaving } \\
\text { traffic flows }\end{array}$ & $\begin{array}{l}\text { Density } \\
\text { [veh/km/lane] }]\end{array}$ & $\begin{array}{l}\text { Necessary to reduce } \\
\text { availability on upper } \\
\text { ramps when traffic } \\
\text { density }>21\end{array}$ \\
\hline $\begin{array}{l}\text { Area of mergers and } \\
\text { branching streams }\end{array}$ & $\begin{array}{l}\text { Density } \\
{[\mathrm{veh} / \mathrm{km} / \mathrm{lane}]}\end{array}$ \\
\hline
\end{tabular}

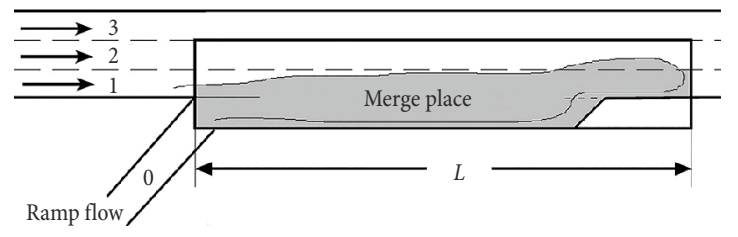

Fig. 2. The study on congestion formation in the merge zone

2001). It defines boundary flow intervals at which the turbulence zone (zone of merger streams) does not lead to the beginning of a growth in the long queues of vehicles. In this case, the main road is represented as a two-lane one and marked as 1 and 2 and the ramp is denoted as 0 . According to simulation conditions, a situation where entry into the main road is not limited has been considered. The analysis of video metering showed that when traffic flow on the ramp made $15-25 \%$ of the flow of the main road, it determined the behaviour of road users in Lane 1, which caused turbulence at a distance from 50 to $300 \mathrm{~m}$. When traffic flow on the ramp exceeds $26 \%$ of the flow of the main road, turbulence partly captures Lane 2, which causes significant reduction in lane capacities and the whole road.

For a number of years, foreign theory and practice has paid particular attention to the adaptive management of transport demand, the main objective of which is to reduce the impact of the adjacent stream (entering the highway). This is necessary to prevent the formation of network congestion on the main lines (Fig. 3).

Adaptive methods for controlling access to the highway will improve the safety merging traffic flows. They allow an increase in highway capacity and a reduction in fuel consumption and toxic emissions released from car exhaust fumes (Highway Capacity Manual 2010). 


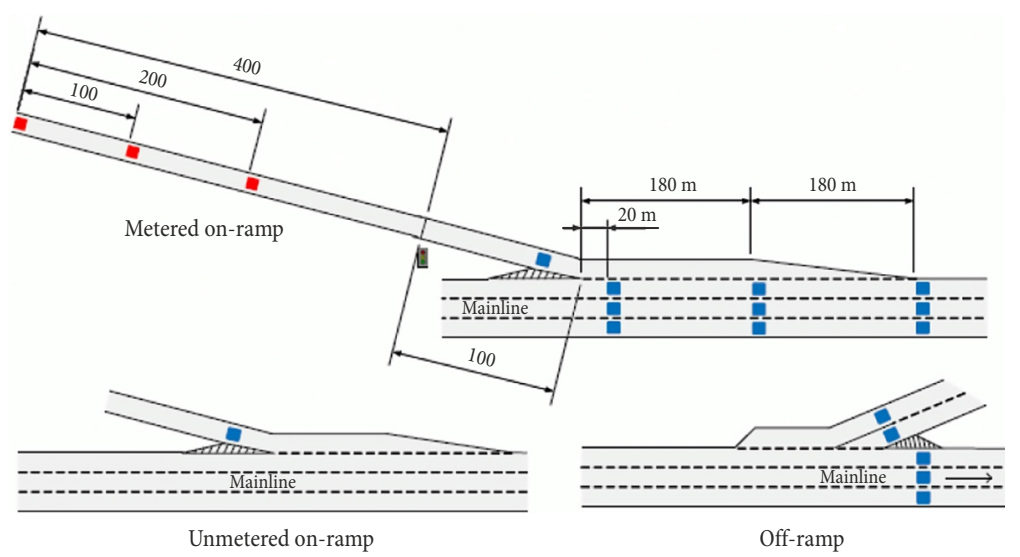

Note 1: 'Blue' loops here are 2 metres long; Note 2: 'Red' loops here are 4.5 metres long;

Note 3: On the mainline, add additional equidistant stations to ensure no length between detectors is greater than 500 metres;

Note 4: Detector schematics not to scale.

Fig. 3. The scheme for adaptive control access to the highway

Their characteristics are determined by the use of the service management strategy (one or more vehicles per cycle) (Table 2, Fig. 4).

The regulation of the entrance order into the highway is seen as the most effective tool for ensuring legal speeds on highways for the safe interaction of flows in merger areas:

- delays in the vehicles traveling on the highway are reduced significantly due to 'shifting' on ramp flows; this is due to an increase in the time of their service at the entrance to the highway and rerun vehicles on alternative routes.

- it is necessary to provide additional space for queuing vehicles considering an approach to the entrance to the highway.

- it is necessary to inform road users about alternative methods for travelling on routes with appropriate bandwidth to service traffic flows outside the line.

- control entry to the highway should be applied in the presence of recurrent congestion; they occur

Table 2. Access Control Management (ACM) strategies

\begin{tabular}{|c|c|c|c|c|}
\hline \multirow{2}{*}{ Strategy } & \multirow{2}{*}{$\begin{array}{l}\text { Number } \\
\text { of lanes on } \\
\text { the ramp }\end{array}$} & \multirow{2}{*}{$\begin{array}{l}\text { Cycle } \\
\text { length } \\
{[\mathrm{s}]}\end{array}$} & \multicolumn{2}{|c|}{ Capacity of } \\
\hline & & & $\begin{array}{l}\text { entrance } \\
\text { [veh/h] }\end{array}$ & $\begin{array}{l}\text { the influence } \\
\text { area [veh/h] }\end{array}$ \\
\hline $\begin{array}{l}\text { One vehicle } \\
\text { per cycle }\end{array}$ & 1 & $4-4.5$ & $240-900$ & 900 \\
\hline $\begin{array}{l}\text { Several } \\
\text { vehicles per } \\
\text { cycle }\end{array}$ & 1 & $6-6.5$ & $\begin{array}{l}240- \\
1200\end{array}$ & $1100-1200$ \\
\hline
\end{tabular}

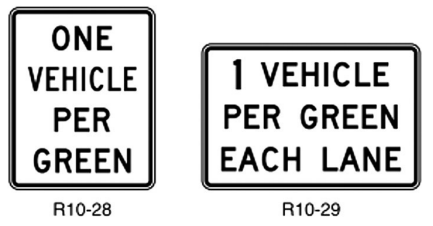

Fig. 4. Access control signs in the USA during the periods of high traffic demand or due to the geometry of the ramp joining the highway that do not meet conditions for movement (no overclocking-speed bandwidth, etc.).

\section{Theoretical Basis of Algorithm for Transport Demand Management}

The basic principle of control over access from the ramp to the highway is a reduction in transport demand. It is based on a certain algorithm.

The inputs of the algorithm are the values of transport demand in highway segments, speeds of free movement and the level of loading the top and bottom of the confluence zone of the streams. Limit on the maximum practical capacity of the ramp is $900 \mathrm{veh} / \mathrm{h}$ (practical minimum makes $240 \mathrm{veh} / \mathrm{h}$ ) (Gordon 2017).

The algorithm for transport demand management can be reduced to the solution of the following application dividing the analysed transport nodal point into several $j$-th segments of the highway and $i$-th segments of the ramp. At least one feeding ramp (adjacent entry) is found in each segment of the highway.

The following relationship defines the value of the main flow:

$$
\begin{aligned}
& q_{j}=\sum_{i=1}^{j} \alpha_{i j} \cdot s_{i}, \\
& \alpha_{i j} \in[0,1],
\end{aligned}
$$

where: $q_{j}$ - the value of traffic flow in the $j$-th section of the highway $[\mathrm{veh} / \mathrm{h}] ; s_{i}$ - the entry flow of the $i$-th ramp [veh/h]; $\alpha_{i j}$ - the share of the flow of the $i$-th ramp passing through the $j$-th section of the highway.

The warning condition of congestion on the $j$-th section of the highway is reduced to the following requirement:

$$
q_{j} \leq c_{j}, \forall_{j},
$$

where: $c_{j}$ - the capacity of the $j$-th section of the highway [veh/h].

The value of RM flow is limited by the following condition: 


$$
s_{i, \min } \leq s_{i} \leq \min \left\{s_{i, \max }, d_{i}\right\} .
$$

where: $d_{i}$ - transport demand for the $i$-th $\operatorname{ramp}[\mathrm{veh} / \mathrm{h}]$; $s_{i, \max }$ - the capacity of the $i$-th $\mathrm{ramp}$ [veh/h].

Thus, a solution to the problem of quadratic programming can match the optimal management of access to the highway. The objective function of the problem is the minimization of the queue length of vehicles on adjacent ramps under the following restrictions on the measured variables:

$$
\begin{aligned}
& q_{j} \leq c_{j}, \forall_{j} ; \\
& q_{j} \leq \sum_{i=1}^{j} \alpha_{i j} \cdot s_{i} ; \\
& s_{i, \min } \leq s_{i} \leq \min \left\{s_{i, \max }, d_{i}\right\} .
\end{aligned}
$$

This task is implemented in the $m$-file (Fig. 5) on the Optimization Toolbox package of MATLAB R2013 software and can be expressed as follows:

$$
\min \left(\frac{1}{2} x^{\prime} \cdot H \cdot x+f^{\prime} \cdot x\right)
$$

with restrictions:

$$
\begin{aligned}
& A x \leq b ; \\
& A e g \times x=b e q
\end{aligned}
$$

and with bilateral restrictions:

$$
l b \leq x \leq u b,
$$

where: $x$ - the vector of estimated parameters $(m \times 1$, $x \geq 0) ; H$ - the Hessian matrix $(m \times m) ; f$ - the vector of the coefficients of the objective function $(m \times 1)$; $A$ the coefficient matrix of inequality constraints $(n \times m)$; Aeq - the coefficient matrix of linear equality constraints $(n \times m) ; b-$ the vector of the right parts of inequality constraints $(n \times 1, b \geq 0)$; beq - the vector of the right parts of inequality constraints $(n \times 1)$; $l b$ - the vector of lower limits of parameters $(m \times 1, l b \geq 0)$; $u b$ - the vector of upper limits $(m \times 1, u b \geq 0)$.

The Hessian matrix is symmetric and positive definite. The elements of matrix $h_{i j}$ are second partial derivatives. The objective function must be convex and differentiable. Considering this problem, the objective function is a sum of the squared residuals of vehicle flow queues, so that the function is differentiable and positive definite.

The values of 'traffic volume dosing' to adjacent ramps are chosen as the primary management tool under the following conditions:

- not to overload highway segments;

- to reduce the total length of the queue for adjacent ramps as much as possible.

The algorithm allows estimating the probability of congestion formation if there is objective information on conditions for traffic flow in each segment of the highway (intensity/density). It should be based on criteria for 'the density of vehicles on the lane', according to the values of ramp flow. Each segment of the highway represents the boundary values of traffic density. In this case, the main flow of traffic conditions can be considered as the worst and promote the high probability of congestion formation.

$$
H(f)=\left[\begin{array}{cccc}
\frac{\partial^{2} f}{\partial x_{1}^{2}} & \frac{\partial^{2} f}{\partial x_{1} \partial x_{2}} & \cdots & \frac{\partial^{2} f}{\partial x_{1} \partial x_{n}} \\
\frac{\partial^{2} f}{\partial x_{2} \partial x_{1}} & \frac{\partial^{2} f}{\partial x_{2}^{2}} & \cdots & \frac{\partial^{2} f}{\partial x_{2} \partial x_{n}} \\
\vdots & \vdots & \ddots & \vdots \\
\frac{\partial^{2} f}{\partial x_{n} \partial x_{1}} & \frac{\partial^{2} f}{\partial x_{n} \partial x_{1}} & \cdots & \frac{\partial^{2} f}{\partial x_{n}^{2}}
\end{array}\right] .
$$

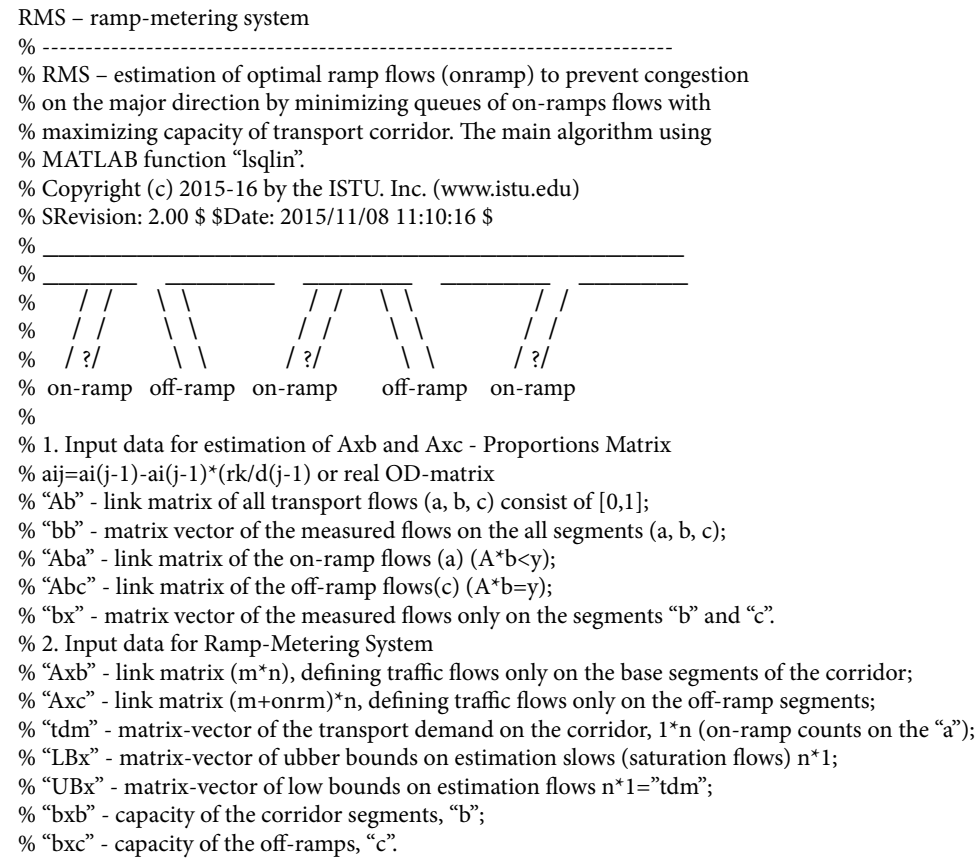




\section{Practical Case Study on the Transport Corridor Area in Vilnius}

Testing the proposed algorithm is performed with reference to the example of the transport corridor area in the suburbs of Vilnius (Lithuania Coordinates: 54.700932, 25.208223) (Figs 6 and 7). Its Western bypass is one of nodal points. In addition, it must be stated that, at the moment, the bypass is still under construction with the estimated completion date ending in spring 2017. When the bypass is finished, traffic flows will inevitably increase, which must be considered in future work.

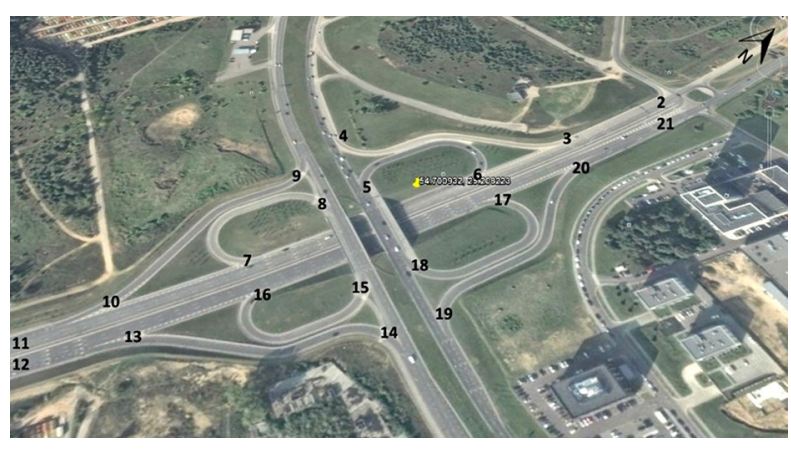

Fig. 6. The general view of the analysed transport nodal point (ㄷ) Google)

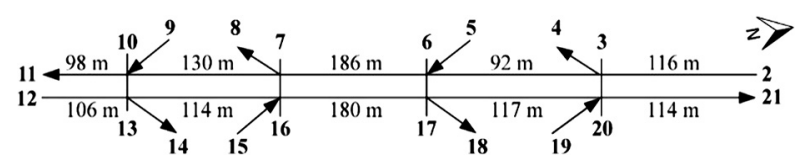

Fig. 7. The presentation of the network section as a directed graph
The aim of the carried out experiment was to assess the maximum possible 15-minute ramp stream (saturation) served under consideration of the transportation nodal point as well as preventing highway segments from overload and a growth in long queues of vehicles on the adjacent ramp.

The reporting section of the road network is represented as a directed graph on the main directions of traffic flow $(2-11,12-21)$ followed by the isolation of supply and unloading ramps (Fig. 8).

The simulation section of the road network was performed in the following two scenarios:

- under the current distribution of traffic without restricting access to the highway (Fig. 9);

- restricted access to the network based on one or more vehicles for a traffic light cycle (Fig. 10).

Basic data: the existing allocation of traffic - 15 min transport demand represented by a matrix of saturation flows (Table 3) - the number of lanes, the length and capacity of the highway segment, including adjacent ramps.

Table 3 shows $A b$ link matrix of all transport flows having form $[0,1]$. Entry flows described as $\mathrm{x}$ from nodes on the highway $(2,12)$ and on-ramps $(5,9,15$, 19) (Fig. 7) are $x 2 \rightarrow, x 12 \rightarrow$ and $x 5 \rightarrow, x 9 \rightarrow, x 15 \rightarrow$, $x 19 \rightarrow$ respectively in the table. All segments are written in simple format, for example: $y 23$, where $y$ - segment, 2 - entry node and 3 - exit node. Green and yellow colours show how traffic flow distributes in intersections (points of the on-ramp or off-ramp), green colour defines a smaller share of traffic flow and yellow - a bigger one. Red colour shows no distribution of traffic flow from the entrance point.

Table 3. The incidence matrix $A b$ (link matrix)

\begin{tabular}{|c|c|c|c|c|c|c|c|}
\hline \multirow{2}{*}{ No } & \multirow{2}{*}{ Segment $j$} & \multicolumn{6}{|c|}{ Entry flow $i$} \\
\hline & & $x 2 \rightarrow$ & $x 5 \rightarrow$ & $x 9 \rightarrow$ & $x 12 \rightarrow$ & $x 15 \rightarrow$ & $x 19 \rightarrow$ \\
\hline 0 & $y 23$ & 1 & 0 & 0 & 0 & 0 & 0 \\
\hline 1 & $y 34$ & 0.1564 & 0 & 0 & 0 & 0 & 0 \\
\hline 2 & $y 36$ & 0.8436 & 0 & 0 & 0 & 0 & 0 \\
\hline 3 & $y 56$ & 0 & 1 & 0 & 0 & 0 & 0 \\
\hline 4 & $y 67$ & 0.8436 & 1 & 0 & 0 & 0 & 0 \\
\hline 5 & $y 78$ & 0.0618 & 0 & 0 & 0 & 0 & 0 \\
\hline 6 & $y 710$ & 0.7818 & 1 & 0 & 0 & 0 & 0 \\
\hline 7 & $y 910$ & 0 & 0 & 1 & 0 & 0 & 0 \\
\hline 8 & $y 1011$ & 0.7818 & 1 & 1 & 0 & 0 & 0 \\
\hline 9 & $y 1213$ & 0 & 0 & 0 & 1 & 0 & 0 \\
\hline 10 & $y 1314$ & 0 & 0 & 0 & 0.108 & 0 & 0 \\
\hline 11 & $y 1316$ & 0 & 0 & 0 & 0.892 & 0 & 0 \\
\hline 12 & $y 1516$ & 0 & 0 & 0 & 0 & 1 & 0 \\
\hline 13 & $y 1617$ & 0 & 0 & 0 & 0.892 & 1 & 0 \\
\hline 14 & $y 1718$ & 0 & 0 & 0 & 0.230 & 0 & 0 \\
\hline 15 & $y 1720$ & 0 & 0 & 0 & 0.662 & 1 & 0 \\
\hline 16 & $y 1920$ & 0 & 0 & 0 & 0 & 0 & 1 \\
\hline 17 & $y 2021$ & 0 & 0 & 0 & 0.662 & 1 & 1 \\
\hline
\end{tabular}


At the first stage, the estimates of the values of loads on the line under current traffic demand were obtained. They confirmed the absence of saturation areas having the highest traffic flow value of $1007 \mathrm{veh} / \mathrm{h}$ in the highway segment (Fig. 8).

The estimates of the maximum possible value of ramp flows (Fig. 9b) and the corresponding values of the load on highway segments (Fig. 9a) in the absence of any restrictions on entry (tolls, traffic signalization, etc.) are obtained at the second stage of simulation.

Fig. 9b shows how different values of maximum traffic flow can be achieved in the nodes of a certain transport nodal point with its unique geometry and traffic parameters. In this case, it is seen that saturation

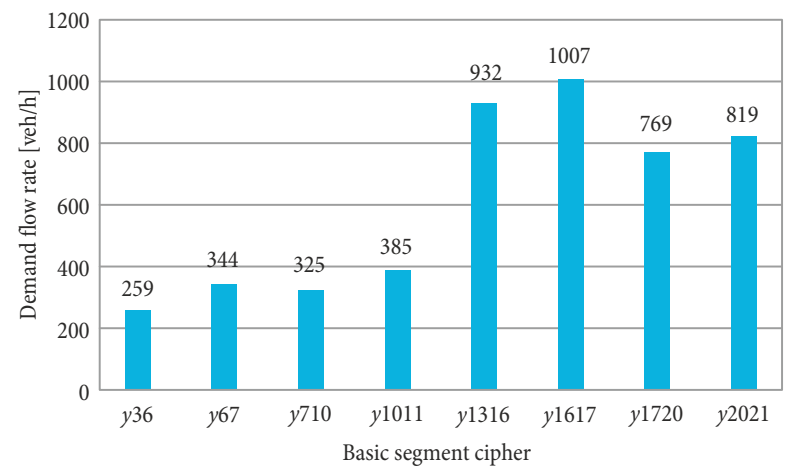

Fig. 8. The evaluation of the load on highway segments with the existing traffic demand

a)

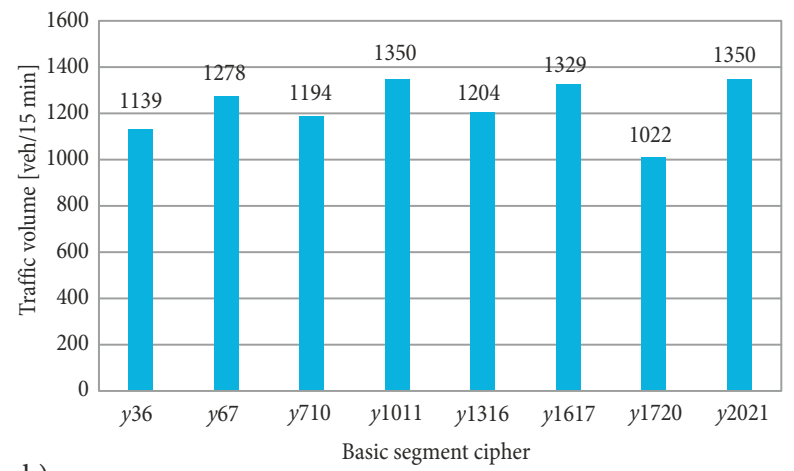

b)

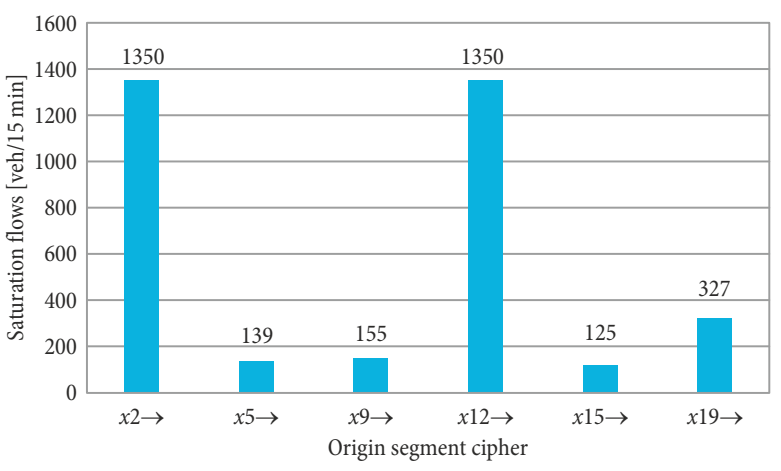

Fig. 9. Maximum saturation flows with the correspondence of the load on highway segments without restricting access to the network: a - the load on highway segments; $\mathrm{b}$ - saturation flows flows on in-ramps have big diversity: $x 15$ has the value of $125 \mathrm{veh} / 15 \mathrm{~min}$ and $x 19-327 \mathrm{veh} / 15 \mathrm{~min}$.

The estimates of the values of ramp flows (Fig. 10b) and the corresponding load on highway segments (Fig. 10a) for the organization of the dosing system for traffic on adjacent entrances are obtained at the third stage of simulation.

Data in Fig. 10 show that there is no big difference between two strategies for managing ramp flows using one or more vehicles per cycle. Slightly better results are achieved implementing a strategy for managing traffic flows that include one vehicle for cycle.

First, we would like to note an obvious advantage of the proposed model. Matrix $A$ has dimension $n>m$, which is full rank. Consequently, the problem has only single local minimum that coincides with the global one. It is also a noteworthy effect on the density (intensity) of the motion of upper limit characterizing the capacity of adjacent ramps. This limit can be used as an effective tool for managing roads of higher categories, from the perspective of applying the following known relationship:

$$
s_{i}=\frac{c_{i} \cdot C_{i}}{g_{i}},
$$

where: $s_{i}$ - the saturation flow of the $i$-th $\mathrm{ramp}[\mathrm{veh} / \mathrm{h}]$; $c_{i}$ - the capacity value of the $i$-th $\mathrm{ramp}[\mathrm{veh} / \mathrm{h}] ; C_{i}-$ the time value of the cycle of the $i$-th ramp $[s] ; g_{i}$ - the duration of the service cycle of the ramp lane $[s]$.

a)

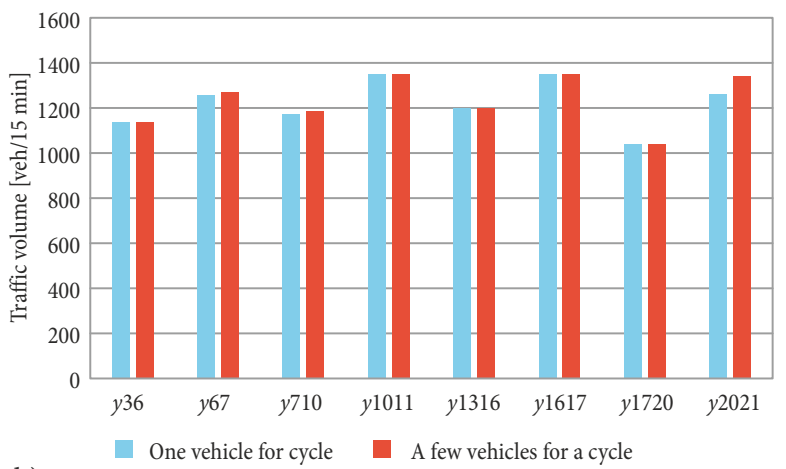

b)

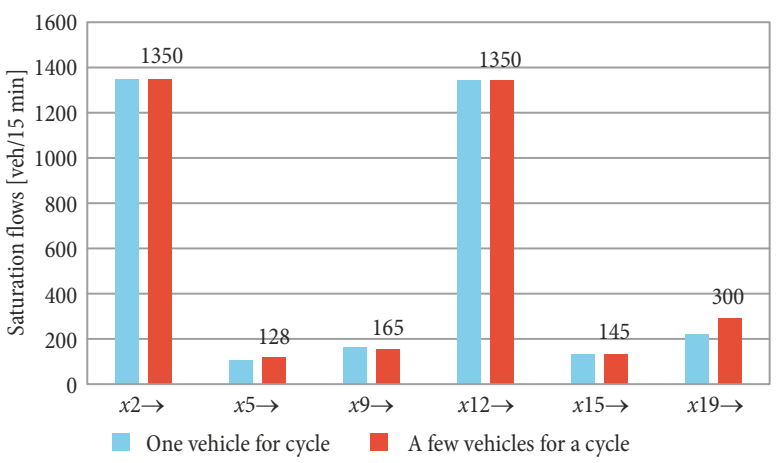

Fig. 10. Saturation flows considering the load on highway segments applying different strategies for managing ramp flows: $a$ - the load on highway segments; $b$ - saturation flows 
In view of the above presented simulation results, practical recommendations presented in Highway $\mathrm{Ca}-$ pacity Manual 2010 (Table 1), suggestions for using one or more vehicles per cycle $g_{i}$ can be submitted.

Considering the quality of source data and its significant impact on the control parameters of the highway, it is very important to have precise information about the distribution of traffic within the corridor (Table 3 ). As test results show, a huge impact on the quality of the control action is provided by:

- actual capacities of highway segments;

- A matrix, which can be made through monitoring precisely registering ramp flow distribution or employing the method for identifying license plate numbers of vehicles.

\section{Conclusions and Future Research}

1. The regulation of the entry order to the highway can be viewed as the most effective tool for ensuring permitted speed and traffic safety in merging areas having in-ramps.

2. The usage of access control management strategies is based on a reduction in transport demand for highway segments. It is based on a certain algorithm, including input parameters such as the value of transport demand in the highway segment, the speed of free movement and the loading level of the upper and lower confluence part of flows. The maximum practical capacity of the ramp lane is $900 \mathrm{veh} / \mathrm{h}$ (practical minimum is $240 \mathrm{veh} / \mathrm{h}$ ).

3. The traffic flow values of 'dosage' from adjacent ramps are selected as the main control parameter under the following conditions:

- not to overload highway segments;

- to minimize the total length of the queue in adjacent ramps.

4. The proposed algorithm estimates the probability of starting congestion formation on the ramp using objective information on traffic conditions in each segment of the highway (strength/density). It is based on the criterion of vehicle density on the lane.

5. A practical case study on a transport nodal point in Vilnius under the current traffic demand confirmed the absence of saturation areas with the highest traffic flow value of $1007 \mathrm{veh} / \mathrm{h}$ on the highway segment.

6. Algorithm calculations have showed different values of maximum traffic flow when $x 15$ has the value of $125 \mathrm{veh} / 15 \mathrm{~min}$ and $x 19-327 \mathrm{veh} / 15 \mathrm{~min}$, which indicates that a certain transport nodal point has its unique geometry and traffic parameters.

7. Algorithm calculations of entrance ramp management between two strategies for controlling traffic flow, i.e. those using one or more vehicles per cycle, demonstrate that a small advantage is visible by implementing the strategy for managing traffic flows that include one vehicle for cycle.

8. Information on the existing distribution of traffic demand on the highway has a significant impact on the quality of simulation; therefore, the authors agreed on setting out:

- a methodology for evaluating the capacity of highway segments (Fig. 2) taking into account the possible interaction of traffic conditions (rebuilding, branching, merging);

- a methodology for evaluating correspondence matrixes of ramp flows based on the methods used for fixing discontinuities in the flow and a genetic optimization algorithm that is the most robust tool for eliminating possible errors in original data.

\section{References}

Gordon, R. 2017. Intelligent Transportation Systems: Functional Design for Effective Traffic Management. 2nd edition. Springer. $300 \mathrm{p}$.

Gregurić, M.; Ivanjko, E.; Galić, I.; Mandžuka, S.; Gold, H. 2014. Urban highways level of service improvement based on intelligent ramp metering, in Central European Conference on Information and Intelligent Systems: 25th International Conference, 17-19 September 2014, Varaždin, Croatia, 296-303.

Hasan, M.; Jha, M.; Ben-Akiva, M. 2002. Evaluation of ramp control algorithms using microscopic traffic simulation, Transportation Research Part C: Emerging Technologies 10(3): 229-256. https://doi.org/10.1016/S0968-090X(02)00005-0

Highway Capacity Manual. 2010. Transportation Research Board. 5th edition. $1650 \mathrm{p}$.

Jacobson, L.; Stribiak, J.; Nelson, L.; Sallman, D. 2006. Ramp Management and Control: Handbook. US Department of Transportation. Federal Highway Administration, Washington, DC. 342 p. Available from Internet: https://ops. fhwa.dot.gov/publications/ramp_mgmt_handbook/manual/manual/pdf/rm_handbook.pdf

Lorenz, M.; Elefteriadou, L. 2001. Defining freeway capacity as function of breakdown probability, Transportation Research Record: Journal of the Transportation Research Board 1776: 43-51. http://dx.doi.org/10.3141/1776-06

Mihajlov, A. Y.; Golovnyh, I. M. 2004. Sovremennye tendencii proektirovaniya i rekonstrukcii ulichno-dorozhnyh setej gorodov. Novosibirsk: Nauka. 267 s. (in Russian).

Papageorgiou, M.; Diakaki, C.; Dinopoulou, V.; Kotsialos, A.; Wang, Y. 2003. Review of road traffic control strategies, Proceedings of the IEEE 91(12): 2043-2067. https://doi.org/10.1109/JPROC.2003.819610

Papamichail, I.; Kotsialos, A.; Margonis, I.; Papageorgiou, M. 2010. Coordinated ramp metering for freeway networks - a model-predictive hierarchical control approach, Transportation Research Part C: Emerging Technologies 18(3): 311331. https://doi.org/10.1016/j.trc.2008.11.002

Park, H. J.; Roess, R. P. 2015. A Study on lane operation restriction (LOR) policy at on-ramp junctions, Procedia Computer Science 52: 592-599. https://doi.org/10.1016/j.procs.2015.05.044

Ringert, J.; Urbanik, T. 1993. Study of freeway bottlenecks in Texas, Transportation Research Record: Journal of the Transportation Research Board 1398: 31-41.

Shawky, M.; Nakamura, H. 2007. Characteristics of breakdown phenomenon in merging sections of urban expressways in Japan, Transportation Research Record: Journal of the Transportation Research Board 2012: 11-19. https://doi.org/10.3141/2012-02

Sun, J.; Ouyang, J.; Yang, J. 2014. Modeling and analysis of merging behavior at expressway on-ramp bottlenecks, Transportation Research Record: Journal of the Transportation Research Board 2421: 74-81. https://doi.org/10.3141/2421-09 